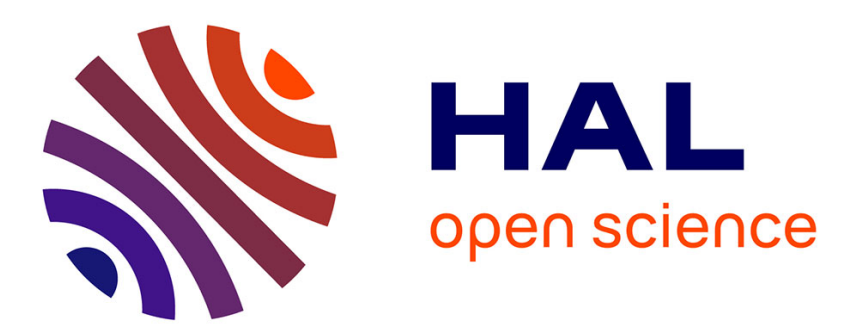

\title{
Towards a sharpest interpretation of analytical results by assessing the uncertainty of PIXE/RBS data at the AGLAE facility
}

Marie Radepont, Quentin Lemasson, Laurent Pichon, Brice Moignard, Claire Pacheco

\section{To cite this version:}

Marie Radepont, Quentin Lemasson, Laurent Pichon, Brice Moignard, Claire Pacheco. Towards a sharpest interpretation of analytical results by assessing the uncertainty of PIXE/RBS data at the AGLAE facility. Measurement, 2018, 114, pp.501-507. 10.1016/j.measurement.2016.07.005 . hal02551097

\section{HAL Id: hal-02551097 \\ https://hal.science/hal-02551097}

Submitted on 18 May 2020

HAL is a multi-disciplinary open access archive for the deposit and dissemination of scientific research documents, whether they are published or not. The documents may come from teaching and research institutions in France or abroad, or from public or private research centers.
L'archive ouverte pluridisciplinaire HAL, est destinée au dépôt et à la diffusion de documents scientifiques de niveau recherche, publiés ou non, émanant des établissements d'enseignement et de recherche français ou étrangers, des laboratoires publics ou privés. 


\title{
Towards a sharpest interpretation of analytical results by assessing the uncertainty of PIXE/RBS data at the AGLAE facility
}

\author{
M. Radepont ${ }^{1,2}$, Q. Lemasson ${ }^{2,3}$, L. Pichon ${ }^{2,3}$, B. Moignard ${ }^{2,3}$, C. Pacheco ${ }^{2,3}$ \\ ${ }^{1}$ Sorbonne Universités, Centre de Recherche sur la Conservation (CRC, USR3224), Muséum national \\ d'histoire naturelle, Ministère de la Culture et de la Communication, CNRS, CP21, \\ 36 rue Geoffroy Saint-Hilaire, 75005 Paris, France.marie.radepont@gmail.com \\ ${ }^{2}$ Centre de Recherche et de Restauration des Musées de France (C2RMF) \\ Palais du Louvre, 14 quai F. Mitterrand, 75001 Paris, France. \\ ${ }^{3}$ Fédération de Recherche 3506 New AGLAE - CNRS/MCC-C2RMF-Palais du Louvre, Paris, France.
}

\begin{abstract}
The advances in object analysis and data processing is a real asset in science and in particular in the cultural heritage field. However, results interpretations depend on the reliability of the information obtained on the archaeological material studied. At the AGLAE facility, a specific methodology using the theory of analysis of variance (ANOVA) was followed in order to calculate the uncertainty of the PIXE and the RBS analyses due to the machine and to the data processing. Repeatability and reproducibility of measurements are studied on three PIXE standards and one RBS standard and the corresponding uncertainties are developed. Then results of RBS analyses on cultural heritage objects are presented to illustrate the discussion.
\end{abstract}

\section{Introduction}

For more than 25 years in Le Louvre premises, non-invasive study of Cultural Heritage materials by ion beam analysis (IBA) at the AGLAE facility gives precious information on their provenance, manufacturing process or conservation state, which are essential issues in archaeology [1-4]. Directly applied in air on objects presenting various sizes, shapes and conservation states, PIXE (Particle Induced X-ray Emission), PIGE (Particle Induced Gamma-ray Emission), RBS (Rutherford Backscattering Spectroscopy) and IBIL (Ion Induced Iono-Luminescence) are IBA signals that can be simultaneously measured at the AGLAE facility [5,6]. Systematic imaging of such complementary information can be made from tens of $\mu \mathrm{m}^{2}$ up to several $\mathrm{cm}^{2}$ area size [5,7-9].

Scientific results presented in lectures or publications should permanently be accompanied with the corresponding uncertainty. In the Cultural Heritage field, this uncertainty of experimental data can be significant, as objects are most of the time heterogeneous, rough, porous etc. [9]. However, appraising these values is of great importance as it allows a discussion on the reliability of the results and of the interpretations made from the experiments.
The uncertainty of experimental data can be divided in two parts: one concerns the object itself (area representation, potential sample collection and preparation) and the other one concerns the analysis (uncertainty due to the instrument and data processing). If the former can be appraised by the users, the latter is of great importance for the AGLAE operators in order to assess the energy stability of the beam and to offer the best experimental conditions to the users. Moreover, the New AGLAE project (grant ANR-10-EQPX-22) aims at automating the accelerator and improving the stabilization of the beam in energy and position. The new beamline will be operational in 2017 and the uncertainty of the measurements is expected to decrease enabling sharpest data interpretations.

However, determining uncertainties is not always easy to reach. For many experiments, two or more analyses are made for each sample or object, or even for each area of an object, in order to present an average result of the experiment. As for each measurement an uncertainty can be calculated from all factors described above, then how will be calculated the uncertainty of the average result for the entire experiment or the entire object? And how this calculation will help assessing the instrument stability and the data processing reliability? 
In order to reach this aim for PIXE and RBS analyses at the AGLAE facility, repeatability and reproducibility methodologies were performed on three reference glasses and on a gold-layered standard, usually reserved to respectively calibrate PIXE and RBS spectra.

\section{Methods}

\subsection{The AGLAE set-up}

Experiments were performed at the AGLAE facility at atmospheric pressure with an external beam composed of protons particles at $3 \mathrm{MeV}$. The beam was $30 \mu \mathrm{m}$ in size with $0.3 \mu \mathrm{C}$ and $0.7 \mu \mathrm{C}$ integrated charge for each run respectively on PIXE and RBS standards.

The beamline nozzle ends with a $100 \mathrm{~nm}$ thick $\mathrm{Si}_{3} \mathrm{~N}_{4}$ window, representing the interface with the atmosphere, and the target was placed at a work distance of $2 \mathrm{~mm}$.

PIXE spectra were collected with one SDD Low Energy X-ray (LE) detector and two SDD High Energy X-ray (HE) detectors, positioned respectively at $45^{\circ}$ and $50^{\circ}$ relative to the beam axis [5]. The LE detector, which had no filter, enabled the detection of light elements thanks to a helium flow whereas each one of the HE detectors was covered by a $50 \mu \mathrm{m}$ thick aluminum filter. In order to obtain the average concentration of each element for the standards, PIXE measurements consisted in one cartography of $500 \times 500 \mu \mathrm{m}^{2}$ on their surface, and one sum spectrum is extracted from each map. The targets presented here are three of the four Corning archaeological reference glasses which chemistry is well known [10]: glass A, B and D.

RBS measurements were performed with a detector collecting backscattered protons set at $130^{\circ}$ with respect to the incident beam (Fig. 1a). The housing of the detector is placed under vacuum and, as for the nozzle, is terminated by a $100 \mathrm{~nm}$ thick $\mathrm{Si}_{3} \mathrm{~N}_{4}$ window. The target is a multi-layered standard composed by a superficial $1.6-\mu \mathrm{m}$-thick layer of gold applied on a $\mathrm{SiO}_{2}$ substrate with in between a 10-nm-thick adhesive chrome layer (Fig. 1b).

\subsection{Data processing for PIXE and RBS analyses}

Particle Induced X-ray Emission (PIXE) analysis is based on the X-ray emission after the atomic interactions between incident charged particles and electrons present in the target. PIXE data were processed using the GUPIXWIN calculation engine [11] coupled to the in-house TRAUPIXE software [9]. The composition of the target obtained from the LE and the HE detectors can be combined by using the iron as the pivot element, which means that it must be present in both spectra. The quantitative composition of the analyzed materials is obtained for matrix and trace elements and, to perform these calculations, the target is assumed to be thick and homogeneous. For the results presented here, only elements quantified as above the detection limit were considered.

The Rutherford Backscattering Spectroscopy is based on the elastic collision between incident charged particles and nucleus of atoms present in the analyzed target [12]. RBS data were processed using the SIMNRA software V6.05. This program aims at simulating RBS spectra (Fig. 2) and comparing them to the experimental ones in order to assess the composition and the thickness of the different layers of the sample analyzed [13]. To simulate a spectrum, once the experimental set-up is defined (see above), the target is described as a succession of layers specifying, for each layer, its thickness and the relative atomic concentration of elements. The value of the thickness is given in Thin Film Unit (TFU), corresponding to $10^{15}$ atoms. $\mathrm{cm}^{-2}$. As for $\mathrm{Au} 1.10^{15}$ atoms.cm ${ }^{-2}$ corresponds to 0.1694 $\mathrm{nm}$, the thickness of a $100 \%-\mathrm{Au}$ layer of in the metric system is expressed from the thickness in TFU by $[12,14]$ :

$e_{n m}=e_{T F U} \times 0.1694$

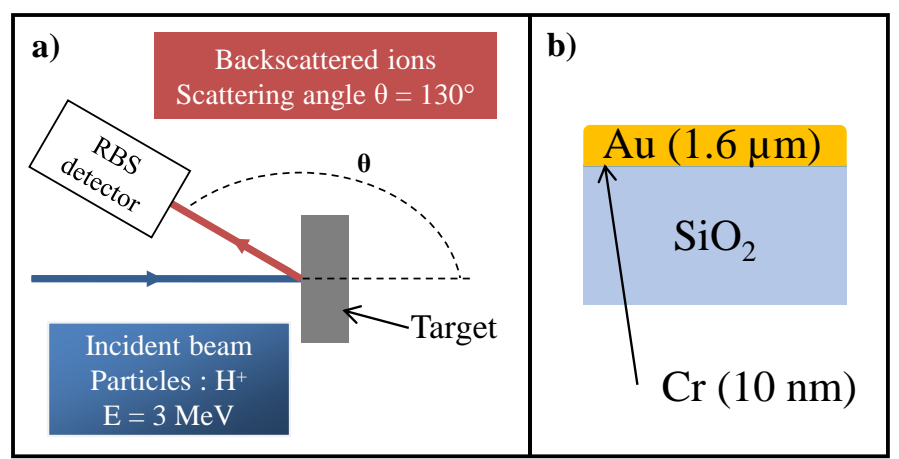

Fig. 1. a) AGLAE set-up for RBS analyses; b) description of the standard used as a target to estimate the uncertainty of RBS analyses due to the instrument and to the data processing. 


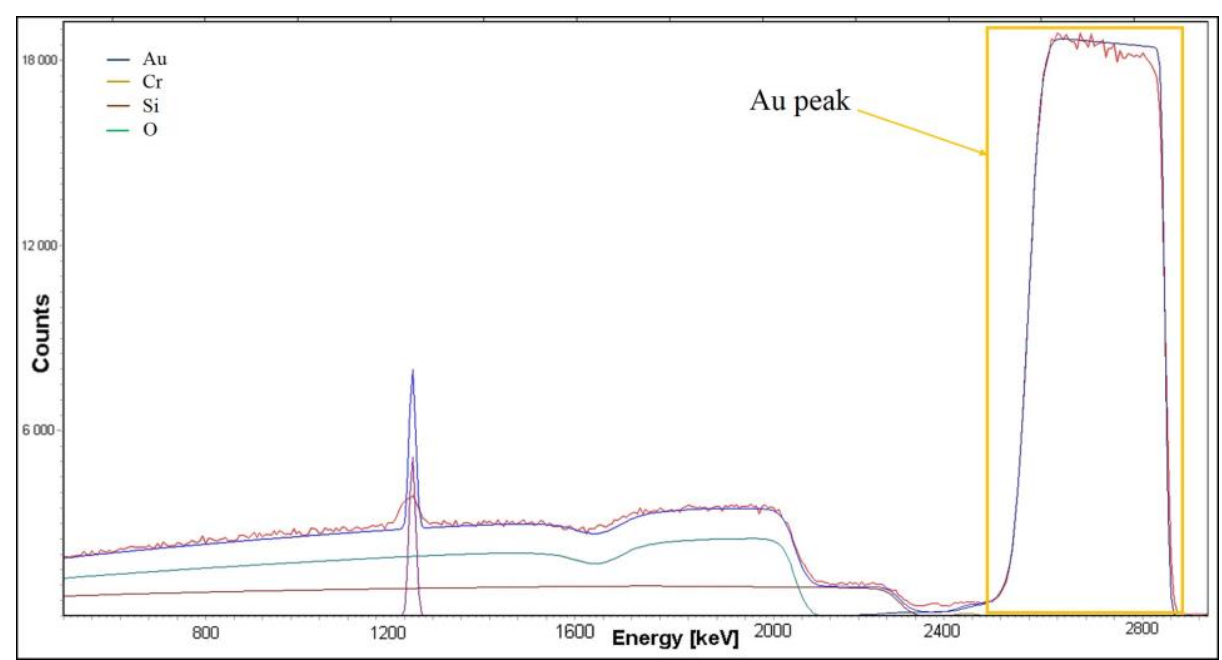

Fig. 2. RBS spectrum obtained with protons at $3 \mathrm{MeV}$ from the Au standard processed by SIMNRA with in red the experimental spectrum and in blue the simulated one.

The aspect of the RBS spectra can be altered by multiple factors, two of them will be discussed here: the porosity of the layers, and the roughness of the surface.

To simulate the first factor, the element of the underlying layer can be added in the porous layer, which will reduce the relative concentration of the elements of the layer. Indeed the porosity of a layer will induce a decrease of the intensity of the peaks coming from the elements present in this layer.

Concerning the second factor, the back edge of the peak of the elements present in the rough layer in the experimental spectrum will not be vertical as the theory would plot it. A specific option is present in the SIMNRA software to simulate its effect on the spectrum: a full width at half maximum (FWHM) can be defined in TFU for the considered layer to determine the width and shape of the thickness distribution (SIMNRA assumes a Gamma distribution of layer thicknesses, resembling a Gaussian distribution visible on the spectra) $[15,16]$. When the simulated spectrum with a defined standard derivation is considered as the closest representation of the experimental spectrum, the uncertainty due to the roughness can be calculated as follow $[15,16]$ :

$\sigma=F W H M / 2.35$

\subsection{The analysis of variance (ANOVA)}

The analysis of variance is a useful technique for the preparation and certification of reference materials in multiple science fields. Indeed, this statistic tool allows the assessment of the homogeneity of groups of data and gives the uncertainty of the values obtained on the materials in order to verify the compliance with requirements [17].

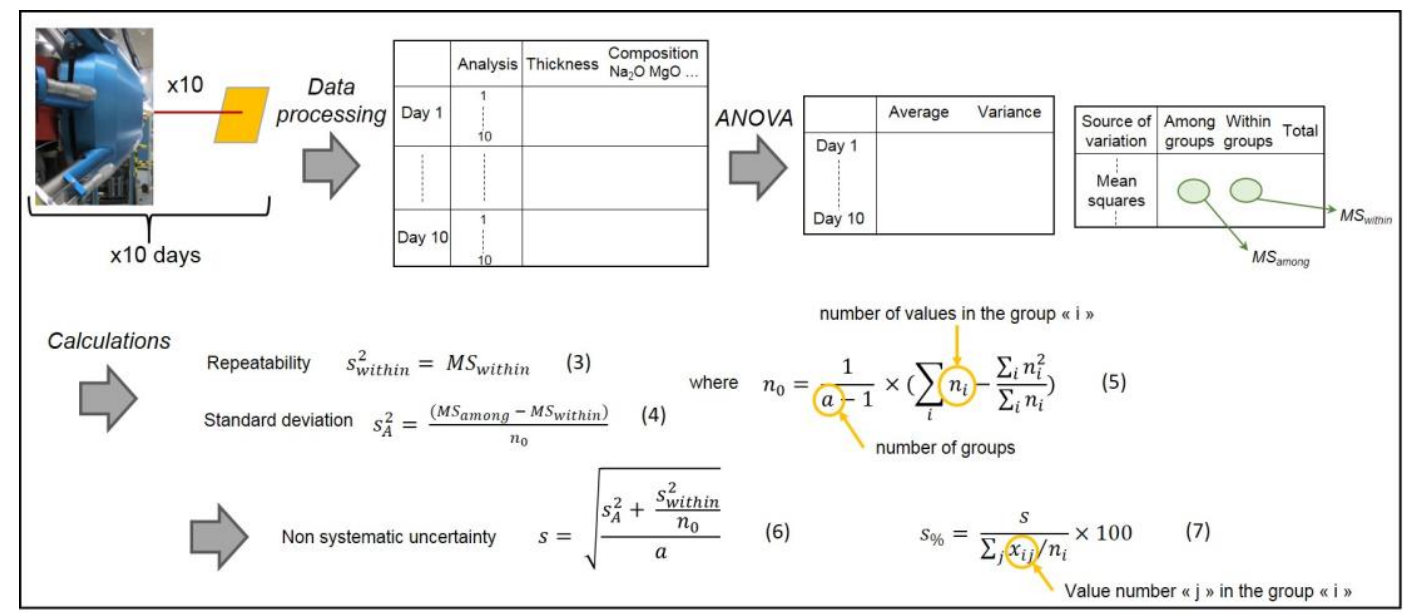

Fig. 3. The different steps of the methodology implemented to obtain the uncertainty of PIXE and RBS analyses at the AGLAE facility. Numbers in brackets indicate the corresponding number of each formula in the text. 
For this study, the ANOVA calculations with one factor were used from the Excel software. Even if in the archaeological field the scattering of results is often studied by the intermediate of the standard deviation, ANOVA uses another value for each group of measurements: the variance. These calculations follow the different formulas giving the sum of squares, the degrees of freedom, the mean squares (MS), the F factor (given by the Snedecor Table), the probability and the critical $F$ value, the third first terms indicated within the different groups of data, and among the same groups [17]. These results can be interpreted by comparing the probability to the significant threshold defined by the user ( 0.05 for our study), or by comparing the $\mathrm{F}$ factor with the critical $F$ value: if critical $F$ value $>F$ factor (probability $>$ threshold) then variances are considered as identical and their relation follows the Fisher-Snedecor law. This consideration is important for further statistic analyses.

From all these ANOVA values, uncertainties of the measurements considered can be estimated (see Fig. $3)$. The repeatability can be expressed by [17]:

$s_{\text {within }}{ }^{2}=M S_{\text {within }}$

The standard deviation at the top level of ANOVA is given by [17]:

$s_{A}^{2}=\left(M S_{\text {among }}-M S_{\text {within }}\right) / n_{0}$

with $\mathrm{n}_{0}$ a function of the degrees of freedom [17]:

$n_{0}=1 /(a-1) \times\left(\Sigma_{i} n_{i}-\left(\Sigma_{i} n_{i}^{2}\right) / \Sigma_{i} n_{i}\right)$

with $a$ the number of groups and $n_{i}$ the number of value in the group " $i$ ".

The non systematic uncertainty, which can be used afterwards for the certification, is then calculated, in the unity of the input values, by:

$s=\sqrt{ }\left(\left(s_{A}^{2}+s_{\text {within }}^{2} / n_{0}\right) / a\right)$

To obtain the value as a percentage, it has to be divided by the global average:

$s \%=s /\left(\Sigma_{j} x_{i j} / n_{i}\right)$

with $x_{i j}$ the value number " $\mathrm{j}$ " in the group " $i$ ".

\section{Results and discussion}

3.1. Uncertainty of PIXE analyses at the AGLAE facility

Thanks to the ANOVA calculation, repeatability and reproducibility of measurements are studied on a 4-month period on three standards routinely used to determine the chemical composition of materials by PIXE.

Each standard was analyzed approximately on the same area during 5 days distributed over 4 months (reproducibility). Each day, 10 PIXE measurements were performed on the same exact area (repeatability). After processing the spectra with GUPIXWIN and calculating the composition of the standards, 5 groups of 10 values per element were processed for each standard by ANOVA.

In the following paragraphs, details concerning only the calculation of the uncertainty related to one trace element (lead) quantification for glass A are presented as an illustration before discussing global results obtained on the three standards.

Table 1. Detailed report for the $\mathrm{Pb}$ quantification in glass A calculated after PIXE analyses.

\begin{tabular}{|c|c|c|c|}
\hline Groups & $\begin{array}{c}\text { Number of } \\
\text { measurements }\end{array}$ & $\begin{array}{c}\text { Average } \\
(\mathrm{ppm})\end{array}$ & Variance \\
\hline Day 1 & 10 & 694 & 272 \\
\hline Day 2 & 10 & 709 & 222 \\
\hline Day 3 & 10 & 724 & 379 \\
\hline Day 4 & 10 & 804 & 2602 \\
\hline Day 5 & 10 & 619 & 528 \\
\hline
\end{tabular}

A detailed report of the data obtained for lead in glass $\mathrm{A}$ is given in Table 1 and the results of the corresponding ANOVA calculation is reported in Table 2. Calculations from the different groups show that averages of lead composition vary from 619 to 804 ppm.

Table 2. ANOVA results obtained on the $\mathrm{Pb}$ quantification in glass A calculated after PIXE analyses.

\begin{tabular}{|c|c|c|c|}
\hline $\begin{array}{c}\text { Source of } \\
\text { variation }\end{array}$ & $\begin{array}{c}\text { Among } \\
\text { groups }\end{array}$ & $\begin{array}{c}\text { Within } \\
\text { groups }\end{array}$ & Total \\
\hline Sum of squares & 174472 & 36028 & 210500 \\
\hline $\begin{array}{c}\text { Degrees of } \\
\text { freedom }\end{array}$ & 4 & 45 & 49 \\
\hline Mean squares & 43618 & 801 & \\
\hline F factor & 54 & & \\
\hline Probability & $1.10^{-16}$ & & \\
\hline F critical & 2.58 & & \\
\hline
\end{tabular}

The global average of these values is $710 \mathrm{ppm}$. The following results are calculated from the values obtained from the ANOVA calculations presented in Table 2. The repeatability, expressed by $\mathrm{s}_{\text {within }}$ (equation (3)), is calculated as $28 \mathrm{ppm}$ and the standard deviation at the top level of ANOVA (equation (4)) is $65 \mathrm{ppm}$. The term $\mathrm{n}_{0}$ (equation (5)) equals to 10 . The result of the equation (6) gave an uncertainty of the lead quantification in glass A of $\mathrm{s}$ $=30 \mathrm{ppm}$, which gives the relative percentage (equation (7)) $\mathrm{s} \%$ x $100=4.2 \%$.

The same calculations were made for the elements 
composing the three reference glasses (see results in Table 3). The uncertainties obtained present an average value for glass $\mathrm{A}, \mathrm{B}$ and $\mathrm{D}$ of respectively $2.80 \%, 2.34 \%$ and $2.72 \%$. The maximum uncertainty obtained is $7.30 \%$ (Table 3). No correlation has been seen between these values and the concentrations of the elements, the area of the peaks or the limit of detection. However, for most of the HE analyses, uncertainties are above the average values (see values in italic in Table 3 ). This is particularly due to the PIXE data processing method with a pivot element used at the AGLAE facility, which implies the propagation of the statistical error made on the concentration of this element ( $\mathrm{Fe}$ here) from the low energy to the high energy.

Table. 3. Concentration uncertainties for the three reference glasses obtained from ANOVA calculations on PIXE results. The ' $\mathrm{X}$ ' indicate that the element considered was not detected in the glass. Concentrations for elements in bold type were extracted from $\mathrm{HE}$ analyses; uncertainties in italic are above the average value for the considered glass.

\begin{tabular}{|c|c|c|c|}
\hline & \multicolumn{3}{|c|}{ Concentration uncertainties } \\
\hline & $\begin{array}{c}\text { Glass } \\
\text { A }\end{array}$ & $\begin{array}{c}\text { Glass } \\
\text { B }\end{array}$ & $\begin{array}{c}\text { Glass } \\
\text { D }\end{array}$ \\
\hline $\mathrm{Na}_{2} \mathrm{O}$ & $1.50 \%$ & $0.60 \%$ & $1.40 \%$ \\
\hline $\mathrm{MgO}$ & $60 \%$ & $70 \%$ & $.00 \%$ \\
\hline $\mathrm{Al}_{2} \mathrm{O}_{3}$ & $.00 \%$ & $.40 \%$ & $.30 \%$ \\
\hline $\mathrm{SiO}_{2}$ & $.40 \%$ & $.40 \%$ & $.10 \%$ \\
\hline $\mathrm{P}_{2} \mathrm{O}_{5}$ & $X$ & $10 \%$ & $.30 \%$ \\
\hline $\mathrm{SO}_{3}$ & $30 \%$ & $10 \%$ & $4.20 \%$ \\
\hline $\mathrm{Cl}$ & $00 \%$ & $00 \%$ & $.80 \%$ \\
\hline $\mathrm{K}_{2} \mathrm{O}$ & $70 \%$ & $40 \%$ & $.50 \%$ \\
\hline & $\%$ & $\%$ & $.50 \%$ \\
\hline $\mathrm{TiO}_{2}$ & $30 \%$ & $90 \%$ & $1.00 \%$ \\
\hline $\mathbf{V}_{2} \mathbf{O}_{3}$ & $X$ & $50 \%$ & $X$ \\
\hline $\mathrm{Cr}_{2} \mathrm{O}_{3}$ & $X$ & $50 \%$ & $\mathrm{X}$ \\
\hline $\mathrm{MnO}$ & $20 \%$ & $.20 \%$ & $2.20 \%$ \\
\hline $\mathrm{Fe}_{2} \mathrm{O}_{3}$ & $3.20 \%$ & $2.60 \%$ & $2.90 \%$ \\
\hline $\mathrm{CoO}$ & $3.40 \%$ & $2.60 \%$ & $3.10 \%$ \\
\hline $\mathrm{NiO}$ & $3.90 \%$ & $.80 \%$ & $3.40 \%$ \\
\hline 0 & $3.70 \%$ & $.90 \%$ & $3.40 \%$ \\
\hline $\mathrm{ZnO}$ & $4.30 \%$ & $.20 \%$ & $3.50 \%$ \\
\hline $\mathrm{As}_{\mathbf{2}} \mathrm{O}_{\mathbf{5}}$ & $X$ & $X$ & $3.90 \%$ \\
\hline $\mathbf{R} \mathbf{b}_{2} \mathbf{O}$ & $5.70 \%$ & $\mathrm{X}$ & $6.70 \%$ \\
\hline SrO & $4.60 \%$ & $20 \%$ & $4.00 \%$ \\
\hline $\mathrm{ZrO}_{2}$ & $X$ & $5.80 \%$ & $3.80 \%$ \\
\hline & $5.50 \%$ & $X$ & $7.30 \%$ \\
\hline & $4.10 \%$ & $5.90 \%$ & $4.30 \%$ \\
\hline & $2.20 \%$ & $2.90 \%$ & $3.00 \%$ \\
\hline $\mathbf{P b O}$ & $4.20 \%$ & $3.40 \%$ & $3.70 \%$ \\
\hline
\end{tabular}

These values represent the uncertainty of an elemental composition obtained by a PIXE analysis performed at the AGLAE facility, including the potential instability of the instrument and the bias due to the data processing with the GUPIXWIN calculation engine.

\subsection{Uncertainty of RBS analyses at the AGLAE facility}

Thanks to the ANOVA calculation, repeatability and reproducibility of measurements are studied on a 4-month period on a standard routinely used to determine the depth repartition of the elements by RBS.

The standard was analyzed approximately on the same area during 10 days distributed over 4 months (reproducibility). Each day, 10 RBS measurements were performed on the same exact point (repeatability). After processing the spectra with SIMNRA (Fig. 2) and calculating the thickness of the Au layer with the equation (1), 10 groups of 10 values were processed by ANOVA.

Table 4. Detailed report of the Au thicknesses of the standard calculated after RBS analyses.

\begin{tabular}{|c|c|c|c|}
\hline Groups & $\begin{array}{c}\text { Number of } \\
\text { measurements }\end{array}$ & $\begin{array}{c}\text { Average } \\
(\mathrm{nm})\end{array}$ & $\begin{array}{c}\text { Variance } \\
\left(\mathrm{nm}^{2}\right)\end{array}$ \\
\hline Day 1 & 10 & 1638 & 489 \\
\hline Day 2 & 10 & 1605 & 40 \\
\hline Day 3 & 10 & 1536 & 71 \\
\hline Day 4 & 10 & 1564 & 98 \\
\hline Day 5 & 10 & 1559 & 51 \\
\hline Day 6 & 10 & 1576 & 40 \\
\hline Day 7 & 10 & 1545 & 52 \\
\hline Day 8 & 10 & 1542 & 110 \\
\hline Day 9 & 10 & 1587 & 107 \\
\hline Day 10 & 10 & 1580 & 119 \\
\hline
\end{tabular}

The detailed report of the data and the results of the ANOVA calculation are respectively reported in tables 4 and 5. The scattering of the results (Fig. 4a) casts doubt on the homogeneity of the standard used in this study. The surface of the target is probably damaged, presenting some holes or reduced thickness on some area. Calculations from the different groups show that, apart from day 1, variances vary from 40 to $120 \mathrm{~nm}^{2}$. The variance reflects the instability of the instrument, which can be sometimes very important (see day 1) and different for every day (Fig. 4b). 
Table 5. ANOVA results obtained on the Au thicknesses calculated after RBS analyses.

\begin{tabular}{|c|c|c|c|}
\hline $\begin{array}{c}\text { Source of } \\
\text { variation }\end{array}$ & $\begin{array}{c}\text { Among } \\
\text { groups }\end{array}$ & $\begin{array}{c}\text { Within } \\
\text { groups }\end{array}$ & Total \\
\hline Sum of squares & 89882 & 10582 & 100464 \\
\hline $\begin{array}{c}\text { Degrees of } \\
\text { freedom }\end{array}$ & 9 & 90 & 99 \\
\hline Mean squares & 9987 & 118 & \\
\hline F factor & 85 & & \\
\hline Probability & $4.10^{-40}$ & & \\
\hline F critical & 1.99 & & \\
\hline
\end{tabular}

The global average of the values is $1573 \mathrm{~nm}(9286$ TFU). The following results are calculated from the values obtained from the ANOVA calculations presented in table 5 . The repeatability, expressed by $\mathrm{s}_{\text {within }}$ (equation (3)), is calculated as $11 \mathrm{~nm}$ and the standard deviation at the top level of ANOVA (equation (4)) is $31 \mathrm{~nm}$. The term $\mathrm{n}_{0}$ (equation (5)) equals to 10 . The result of the equation (6) gave an uncertainty of the thickness of this Au layer of $\mathrm{s}=$ $10 \mathrm{~nm}$ (59 TFU), which gives in percentage (equation (7)) $\mathrm{s} \% \mathrm{x} 100=0.6 \%$.

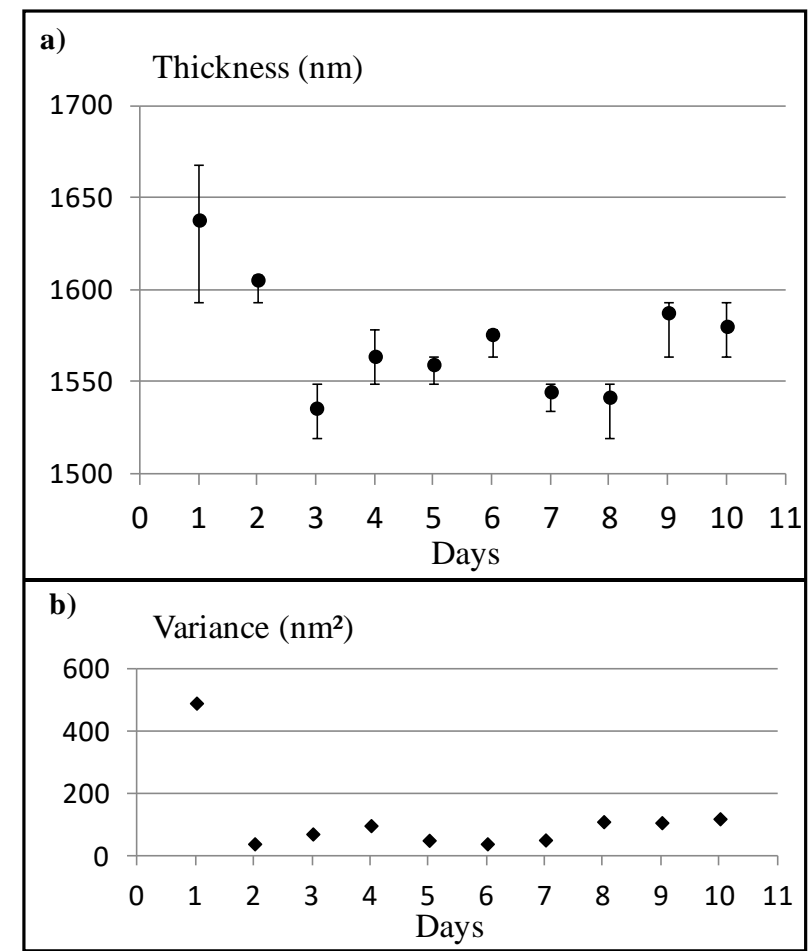

Fig. 4. a) Averages of the thicknesses for each day of experiment. The vertical error scales represent the scattering of the values for each day; b) Variances of thicknesses calculated for each day.

These values represent the uncertainty of a thickness obtained by a RBS analysis performed at the AGLAE facility, including the potential instability of the instrument and the bias due to the data processing with the software SIMNRA.

However, as the standard is dating from a few years, these results can be improved by performing the same study on relatively new standards which would present a better homogeneity in the Au layer (thickness, porosity and roughness) characterized by complementary techniques (SEM-FEG, XPS, AFM).

\subsection{Reliability of RBS data interpretations}

In spite of the instability of the instrument, the uncertainty calculated above by ANOVA (0.6 \%) is quite low compared to the scattering of the thickness ones $(148 \mathrm{~nm})$. However, other factors can alter the spectrum and change the values of thickness of various layers.

Modern silver leaves (closed to the way ancient ones were made) were analyzed with the same methodology and experimental set-up described above. Even if they are modern and not altered, these leaves present different features of roughness and especially of porosity on their surface. Indeed the intensity of the silver peak is different from one leaf to another which implies a change in the atomic percentage of silver in the corresponding layer and then a change in the calculation of the thickness. RBS spectra were processed by SIMNRA and the thickness of silver were calculated from the simulations obtained with the equation (1) applied to silver (for $\mathrm{Ag} 10^{15}$ atoms.cm $\mathrm{cm}^{-2}$ corresponds to $0.1711 \mathrm{~nm}$ ) weighted by the atomic percentage of the silver in the layer. For every sample, roughness of the surface of the target had to be added to the simulation in order to fit closely to the experimental spectrum (Fig. 5).

The average value of the calculated thickness is $206 \mathrm{~nm}$ and the average uncertainty calculated is 39 $\mathrm{nm}(19 \%)$. This result is relatively close to $223 \mathrm{~nm}$, the thickness expected from the information given by the supplier (Dauvet, France). Even on this modern material, the uncertainty due to the analysis at the AGLAE facility is negligible compared to the relatively low one due to the roughness of the sample analyzed.

Analyses on historic or archaeological objects can present an even more important difference.

\subsection{Application to Cultural Heritage questions}

Analyzing historic or archaeological objects implies even more complicated data processing and interpretations. First, the positioning of the objects in front of the beam is made by visualizing the beam on the surface with the induced luminescence of the 


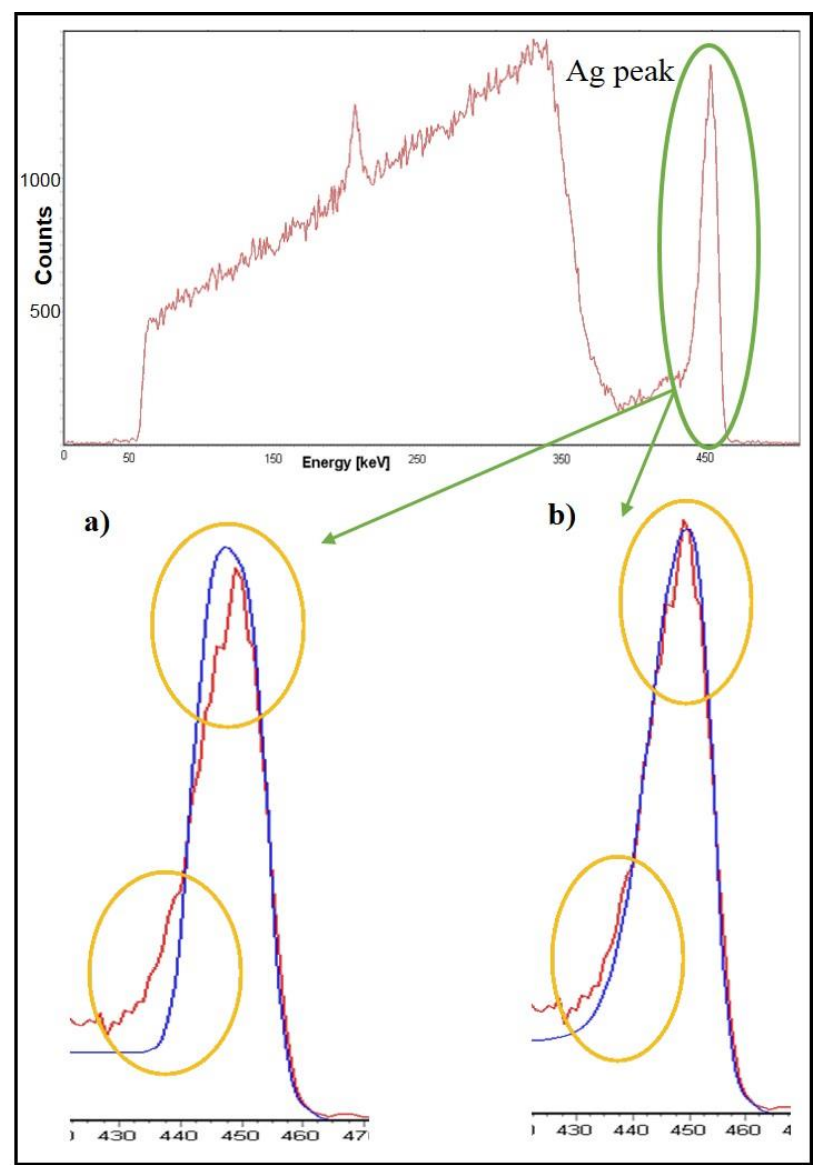

Fig. 5. RBS spectra obtained from analyses with $3 \mathrm{MeV}$ protons of an historic gilt leather, processed by SIMNRA, showing in red the experimental spectra and in blue the simulated one, a) without the simulation of the roughness and $b$ ) with a thickness distribution to simulate the roughness of the surface.

material. However, when materials do not show any luminescence under the beam, the positioning is made with a laser, which might induce greater uncertainties on the results obtained. Moreover, archaeological objects often present a curved or rough surface. An example of calculation of uncertainties of foil thicknesses due to the roughness of the surface of historic objects is presented below.

Studying the thickness of layers is one of the multiple possibilities for a scientist to answer some specific questions in the Cultural Heritage field. RBS analyses present several advantages, especially at the AGLAE facility where the beam is air extracted and sampling is not necessary.

In the CORDOBA project, the study focuses on silver leaves applied on leather and covered by a yellow varnish to form gilt leathers, which are famous and luxurious decorations used from the $16^{\text {th }}$ to the $18^{\text {th }}$ century all over Europe $[18,19]$. The hypothesis is that the characteristics of the silver, and in particular the composition and thickness of the leaf, could lead historians towards the provenance of the object [4].
To reach that aim, a corpus of 45 historic gilt leathers fragments or samples were analyzed at the AGLAE facility with the set-up described above. RBS spectra were processed by SIMNRA and thicknesses of silver were calculated from the simulations obtained by the same calculation as described above. For every sample, roughness of the surface of the target had to be added to the simulation in order to fit closely to the experimental spectrum (Fig. 5). The uncertainty due to this roughness was then calculated following the equation (2).

Analyses of these historic samples showed that results are scattered and the uncertainties are relatively high on average. This can be explained by the evolution of the objects within the exposure time which could imply the presence of silver corrosion at the surface or a lack of material due to degradations or restoration campaigns. For example, for a decoration produced in the Netherlands in the early $17^{\text {th }}$ (gilt-leather 1 in Fig. 6), the average thickness is $123 \mathrm{~nm}$ but the average uncertainty is calculated at $46 \mathrm{~nm}(37 \%)$. Another fragment also produced in the Netherlands but in the $18^{\text {th }}$ century 
(gilt-leather 2 in Fig. 6) showed a thicker silver leaf at $234 \mathrm{~nm}$ with an uncertainty of $77 \mathrm{~nm}(33 \%)$. Next to these uncertainties due to the roughness of the surface of the samples, the ones due to the instability of the instrument (respectively 0.7 and $1.4 \mathrm{~nm}$ for gilt-leather 1 and 2) are negligible. Thus, considering these uncertainties, the first thickness could be $123+46+0.7=169.7 \mathrm{~nm}$ and the second one 234-77-1.4=155.6 nm.

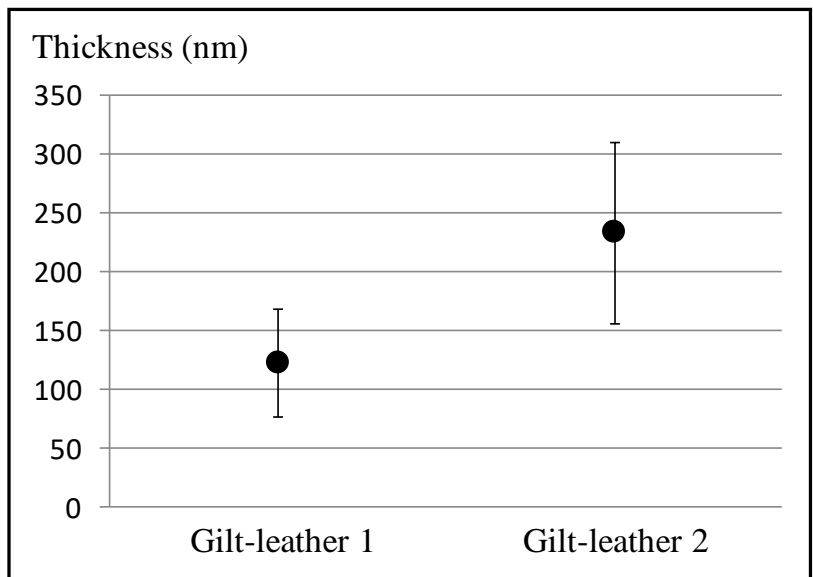

Fig. 6. Thicknesses calculated for the two historic gilt-leathers. The vertical error scales represent the uncertainty of the value due to the roughness of the surface of each sample.

In this context, the consideration of the uncertainties is of great importance before comparing data and jumping to conclusions and care is necessary to interpret analytical data.

\section{Conclusion}

Repeatability and reproducibility measurements during PIXE and RBS analyses over a 7 months period were performed at the AGLAE facility. From these experiments, uncertainties were calculated from ANOVA. These values concern the instrument and the data processing, but not the characteristics of the target itself, which should also be taken into account in the interpretations of the results. In the archaeological field, objects present most of the time a heterogeneous surface, then, as for the example of gilt-leathers presented here, the instrument uncertainty would probably be negligible next to the one due to the roughness, the porosity, the alteration or to other characteristics of the target.

The uncertainties obtained on the composition of the reference glasses from PIXE analyses are situated below $7.5 \%$ for minor and trace elements (with a relative concentration below 1\%), and below $4.5 \%$ for major elements. More PIXE analyses are currently in progress at AGLAE in order to verify these values with more statistics and more reference samples.

Concerning RBS analyses, the uncertainty calculated is far less important. However, this study was performed on a relatively aged standard. These calculations will be reconsidered with new standards currently under preparation in collaboration with the Institut Lavoisier de Versailles. Homogeneity and roughness will be checked by other analytical techniques (SEM-FEG, XPS, AFM).

This study is of very high interest for the future AGLAE experiments. As the New AGLAE beamline will be operational in 2017, uncertainties are expected to decrease. Uncertainty due to the positioning of the objects should also be reduced in the future as, under the scope of the IPERION project, a specific tool will be implemented to assure the perpendicularity of the object towards the beam, especially during mapping analyses. The methodology used in this study can be extended to other ion beam analytical techniques present on the instrument (PIGE, IBIL) by analyzing specific and corresponding standards. ANOVA and the corresponding calculations of uncertainty could also be applied to any type of results and analyses in the future in order to offer the possibility of a better discussion on data reliability and interpretation.

\section{Acknowledgements}

This study was performed under the scope of the CORDOBA project, funded by the Fondation des Sciences du Patrimoine and the LabEx PATRIMA. The authors are grateful to Laurianne Robinet and Céline Bonnot-Diconne for providing the samples of gilt leathers.

\section{References}

[1] J.C.Dran, J.Salomon, T.Calligaro, P.Walter, "Ion beam analysis of art works: 14 years of use in the Louvre", Nucl. Instr. and Meth. in Phys. Res. B, vol.219-220, 2004, pp.7-15.

[2] M.Morelle, Y.El Masri, C.Heitz, R.Prieels, J.Van Mol, J.C.Dran, J.Salomon, T.Calligaro, M.Dubus, "PIXE and RBS applied to cultural heritage objects: Complementary and limitations", Nucl. Instr. and Meth. in Phys. Res. B, vol.240, 2005, pp.600-605.

[3] L.Beck, "Recent trends in IBA for cultural heritage studies", Nucl. Instr. and Meth. in Phys. Res. B, vol.332, 2014, pp.439-444.

[4] C.Bonnot-Diconne, L.Robinet, C.Pacheco, M.Iole, M.Paris, "Multi-technique analysis of gilt-leather wall coverings $\left(16^{\text {th }}-18^{\text {th }}\right.$ centuries)", ICOM-CC $17^{\text {th }}$ Triennal Conference Preprints, Melbourne, 15-19 September 2014, ed. J. Bridgland, art. 0701, Paris: International 
Council of Museums (ISBN 978-92-9012-4108), 2014, 8pp.

[5] L.Pichon, B.Moignard, Q.Lemasson, C.Pacheco, P.Walter, "Development of a multidetector and a systematic imaging system on the AGLAE external beam", Nucl. Instr. and Meth. in Phys. Res. B, vol.318, 2014, pp.27-31.

[6] L.Pichon, T.Calligaro, V.Gonzalez, Q.Lemasson, B.Moignard, C.Pacheco, "Implementation of ionoluminescence in the AGLAE scanning external microprobe", Nucl. Instr. and Meth. in Phys. Res. B, vol.348, 2015, pp.68-72.

[7] Q.Lemasson, B.Moignard, C.Pacheco, L.Pichon, M.F.Guerra, "Fast mapping of gold jewellery from ancient Egypt with PIXE: Searching for hard-solders and PGE inclusions", Talanta, vol.143, 2015, pp.279-286.

[8] M.Albéric, K.Müller, L.Pichon, Q.Lemasson, B.Moignard, C.Pacheco, E.Fontan, I.Reiche, "Non-invasive quantitative micro-PIXERBS/EBS/EBS imaging reveals the lost polychromy and gilding of the Neo-Assyrian ivories from the Louvre collection", Talanta, vol.137, 2015, pp.100-108.

[9] L.Pichon, Q.Lemasson, B.Moignard, C.Pacheco, "Programs for visualization, handling and quantification of PIXE maps at the AGLAE facility", Nucl. Instr. and Meth. in Phys. Res. B, vol.363, 2015, pp.48-54.

[10] E.P.Vicenzi, S.Eggins, A.Logan, R.Wysoczanski, "Microbeam characterization of Corning archeological reference glasses: new additions to the Smithsonian microbeam standard collection", J. Res. Natl. Inst. Stand. Technol., vol.107, 2002, pp.719-727.
[11] J.L.Campbell, N.I.Boyd, N.Grassi, P.Bonnick, J.A.Maxwell, "The Guelph PIXE software package IV", Nucl. Instr. and Meth. in Phys. Res. B, vol.268, 2010, pp.3356-3363.

[12] L.C.Feldman, J.W.Mayer, "Fundamentals of surface and thin film analysis", North-Holland, Elsevier Science Publishing Co., Inc, 1986, $354 \mathrm{pp}$.

[13] W.Eckstein, M.Mayer, "Rutherford backscattering from layered structures beyond the single scattering model", Nucl. Instr. and Meth. in Phys. Res. B, vol.153, 1999, pp.337344.

[14] C.Pacheco, "Etude de films d'or sur matière vitreuse. Application à la céramique glaçurée islamique médiévale. Asie centrale $\mathrm{XIV}^{\mathrm{e}}-\mathrm{XV}^{\mathrm{e}} \mathrm{s}$. - Iran XII ${ }^{\mathrm{e}}$-XIII ${ }^{\mathrm{e}}$ s. ", PhD thesis Université Michel de Montaigne Bordeaux 3, 2007, 250pp.

[15] M.Mayer, «SIMNRA User's Guide », Report IPP 9/113, Max-Planck-Institut für Plasmaphysik, Garching, Germany, 1997.

[16] M.Mayer, "Ion beam analysis of rough thin films", Nucl. Instr. and Meth. in Phys. Res. B, vol.194, 2002, P.177.

[17] A.M.H.Van der Veen, J.Pauwels, "Uncertainty calculations in the certification of reference materials. A. Principles of analysis of variance", Accred Qual Assur, vol.5, 2000, pp.464-469.

[18] A.D.Fougeroux de Bondaroy, "L'art de travailler les cuirs dorés et argentés", Description des arts et métiers, Paris: Guérin et Delatour, 1762, 42pp.

[19] J.P.Fournet, "Les cuirs dorés anciens en France", Mémoire de Recherche approfondie, $\mathrm{PhD}$ thesis, Ecole du Louvre, Paris, 2004. 